\title{
E-band Microwave Radios for Mobile Backhaul
}

\author{
Saad Z. Asif \\ Islamabad, Pakistan
}

\begin{abstract}
This article explores the emerging high capacity microwave radios that operate in $70-90 \mathrm{GHz}$ frequency band to address the mobile backhaul challenge of the cellular industry of Pakistan. The challenge will be look from both technical and business perspectives covering topics like frequency assignments, radio capacity, and experimental results. In hindsight these millimeter wave microwave radios provide an alternative (particularly to optical fiber) to address the said challenge of one of the lowest ARPU (average revenue per user) markets of the world.
\end{abstract}

Index Terms: Microwave Radio, E-band, Mobile Backhaul, 3G, LTE, 4G, 5G.

(C) 2015 Published by MECS Publisher. Selection and/or peer review under responsibility of the Research Association of Modern Education and Computer Science

\section{Background}

Vast majority of the current microwave radios in the world operate in 6-38 GHz frequency bands and are predominantly used to backhaul traffic in mobile networks. As the demands grew, 42 and $70 / 80 \mathrm{GHz}$ frequency bands were recently added to the list.

The microwave radio network in Pakistan is heavily deployed to cater the backhauling of traffic from the cell sites to BSC/RNC/EPC (Base Station Controller/Radio Network Controller/Evolved Packet Core) locations. It is normally takes two three traffic aggregation sites to reach the BSC/RNC/EPC location. The mobile backhaul [1], though there is no standard definition or configuration, is routinely defined as an area between BTS and to a traffic aggregation site and/or to the BSC/RNC/EPC location as shown in Fig. 1. The traffic can be backhauled in variety of way but for the most part in the cellular networks is carried either through microwave radios or optical fiber. In the case of Pakistan even after the launch of $3 \mathrm{G}$ and $4 \mathrm{G}$ services (which were pending for many years) the traffic is still carried through low to mid capacity microwave radios that operate in 6-38 $\mathrm{GHz}$ frequency spectrum. Currently, there are over 31,000 cell sites and 63,000 microwave radio hops deployed in the country.

\footnotetext{
* Corresponding author. Tel.:

E-mail address: szasif@hotmail.com
} 


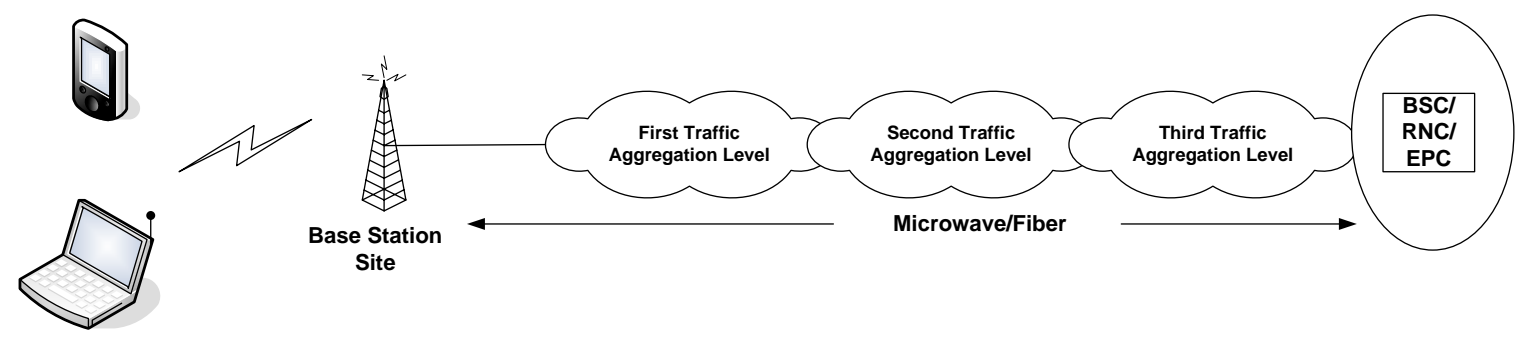

Fig.1. Mobile backhaul

The mobile wireless broadband market in the country is in the infancy stage. The 3G-UMTS service was launched by four cellular players in mid 2014 while 4G-LTE by two in late 2014. There are five cellular operators in the country; one player is offering both $3 \mathrm{G}$ and $4 \mathrm{G}$ service while the smallest player (in terms of subscribers) is only offering 4G service. The fixed wireless broadband market which runs on CDMA2000 EVDO and WiMAX has been around for more than eight years but its penetration rate is less than 2\% [2]. According to Pakistan Telecommunications Authority there were more than 13 million 3G/4G subscribers at the end of April 2015 [2]. Although there is considerable increase in the number of users and data usage since the launch of $3 \mathrm{G} / 4 \mathrm{G}$, however, the increase in revenue is like a drop in the ocean.

The article is divided into four key sections defining radio technology and product aspects of 70/80 GHz microwave radios in section 2 and 3 respectively, experimental results in section 4, while the feasibility of such radios for the country is presented in section 5 .

\section{E-band Radio Technology}

The most suitable frequency band that has been identified for such radios is in the range of 71-76 and 81-86 $\mathrm{GHz}$ which falls under E-band ${ }^{\mathrm{a}}$. The ECC (Electronic Communications Committee) within CEPT (European Conference of Postal and Telecommunications Administration) has defined frequency channel arrangements with ECC Recommendation (05)07 [3].

The $5 \mathrm{GHz}$ band in each direction is divided into 19 channels. Each such channel is $250 \mathrm{MHz}$ wide and two or more channels can be combined to form a single channel of larger size. This channel size is quiet large as compared to the widely deployed microwave radio units which operate with 7 to $56 \mathrm{MHz}$ wide channels. The specified channels can be used to form either TDD or FDD systems within the single band or in combination with the two bands respectively.

The principle of using the channels from within the bands $71-76 \mathrm{GHz}$ and $81-86 \mathrm{GHz}$ in a single duplex FDD arrangement is described in the Fig. 2.

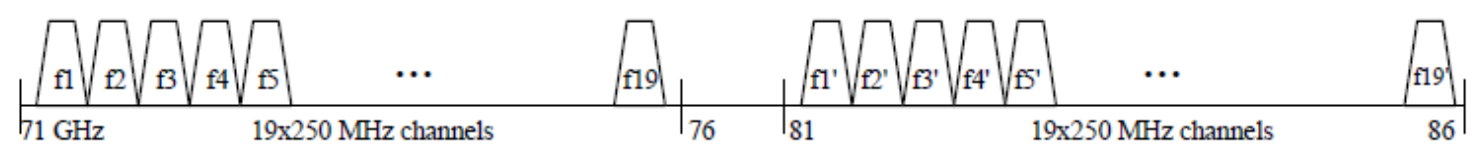

Fig.2. Combining the channels from 71-76 / 81-86 GHz bands into a single FDD arrangement with duplex separation of $10 \mathrm{GHz}$ [3]

The alternative approach is channel aggregation where multiples of $250 \mathrm{MHz}$ channels are aggregated into

\footnotetext{
${ }^{a}$ The waveguide $\mathrm{E}$ band is the range of radio frequencies from $60 \mathrm{GHz}$ to $90 \mathrm{GHz}$ in the electromagnetic spectrum [4].
} 
FDD channels with duplex separation equal or more than $10 \mathrm{GHz}$ is shown in Fig. 3.

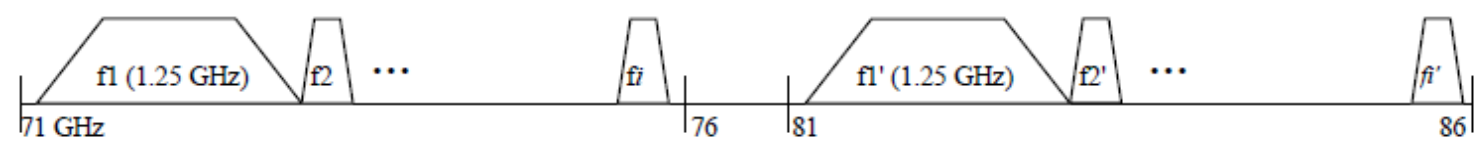

Fig.3. Example of aggregating multiple $250 \mathrm{MHz}$ channels, possibly alongside with original $250 \mathrm{MHz}$ wide channels [3]

\subsection{Radio Interface Capacity}

The second technology element is radio interface capacity (RIC) which depends on the modulation scheme. The ETSI EN 302 217-3 [5] comes handy in this case that explains characteristics and requirements for pointto-point digital fixed radio systems operating in higher frequency bands (including frequencies under discussion). The standard defines six different modulation states as system spectral efficiency classes of operation. However, there is no limitation on spectral efficiency and modulation format and the following Table1 only shows a typical set of such values.

Table 1. System spectral efficiency classes of operation used in this clause [5]

\begin{tabular}{|c|c|c|c|c|c|c|}
\hline Spectral Efficiency Class & $\begin{array}{l}128 \text { States } \\
\text { Modulation } \\
\end{array}$ & $\begin{array}{l}\text { 64 States } \\
\text { Modulation } \\
\end{array}$ & $\begin{array}{l}32 \text { States } \\
\text { Modulation } \\
\end{array}$ & $\begin{array}{l}16 \text { States } \\
\text { Modulation } \\
\end{array}$ & $\begin{array}{l}4 \text { States } \\
\text { Modulation }\end{array}$ & $\begin{array}{l}\text { 2 States } \\
\text { Modulation }\end{array}$ \\
\hline & $5(128)$ & $5(64)$ & $4 \mathrm{H}$ & $4 \mathrm{~L}$ & 2 & 1 \\
\hline
\end{tabular}

Table 2. Typical RIC Values for the Spectral efficiency classes [5]

\begin{tabular}{|c|c|c|c|c|c|c|}
\hline \multirow{2}{*}{$\begin{array}{c}\text { Aggregate } \\
\text { Channel } \\
(\mathrm{MHz})\end{array}$} & \multicolumn{6}{|c|}{ Typical RIC values (Mbps) } \\
\hline & $\begin{array}{c}\text { Class } \\
5(128)\end{array}$ & $\begin{array}{l}\text { Class } \\
\mathbf{5 ( 6 4 )}\end{array}$ & Class $\mathbf{4 H}$ & Class $4 \mathrm{~L}$ & Class 2 & Class 1 \\
\hline 250 & 1000 & 900 & 750 & 600 & 300 & 150 \\
\hline 500 & 2000 & 1800 & 1500 & 1200 & 600 & 300 \\
\hline 750 & 3000 & 2700 & 2250 & 1800 & 900 & 450 \\
\hline 1000 & 4000 & 3600 & 3000 & 2400 & 1200 & 600 \\
\hline 1250 & 5000 & 4500 & 3750 & 3000 & 1500 & 750 \\
\hline 1500 & 6000 & 5400 & 4500 & 3600 & 1800 & 900 \\
\hline 1750 & 7000 & 6300 & 5250 & 4200 & 2100 & 1050 \\
\hline 2000 & 8000 & 7200 & 6000 & 4800 & 2400 & 1200 \\
\hline 2250 & 9000 & 8100 & 6750 & 5400 & 2700 & 1350 \\
\hline 2500 & 10000 & 9000 & 7500 & 6000 & 3000 & 1500 \\
\hline 2750 & 11000 & 9900 & 8250 & 6600 & 3300 & 1650 \\
\hline 3000 & 12000 & 10800 & 9000 & 7200 & 3600 & 1800 \\
\hline 3250 & 13000 & 11700 & 9750 & 7800 & 3900 & 1950 \\
\hline 3500 & 14000 & 12600 & 10500 & 8400 & 4200 & 2100 \\
\hline 3750 & 15000 & 13500 & 11250 & 9000 & 4500 & 2250 \\
\hline 4000 & 16000 & 14400 & 12000 & 9600 & 4800 & 2400 \\
\hline 4250 & 17000 & 15300 & 12750 & 10200 & 5100 & 2550 \\
\hline 4500 & 18000 & 16200 & 13500 & 10800 & 5400 & 2700 \\
\hline 4750 & 19000 & 17100 & 14250 & 11400 & 5700 & 2850 \\
\hline
\end{tabular}

Table 2 shows the RIC values in one direction for such radios in the FDD mode. The TDD systems would match that capacity as the sum of the capacities in both directions. A maximum of $19 \mathrm{Gbps}$ is possible in a 4.75 
GHz channel with 128-QAM (Quadrature Amplitude Modulation) and with equipment compliant to the ETSI standard. So, if an operator has access to $500 \mathrm{MHz}$ bandwidth it can carry a maximum of 2 Gbps of traffic in one direction of a point-to-point radio link.

\subsection{Other Parameters}

The ETSI EN 302 217-3 standard has also defined receiver power density levels (RSL) for BER (bit error rate) $<=10^{-6}$ and $<=10^{-8}$, and co-channel and adjacent channel interference sensitivity. The other key parameters include [5]:

- Maximum EIRP (Equivalent Isotropic Radiated Power) $)^{\mathrm{b}}: \leq+85 \mathrm{dBm}$ (Decibel-milli-watt) for $\mathrm{G}_{\text {ant }} \geq 55$ $\mathrm{dBi}$ (Decibel-isotropic)

- Minimum Antenna gain $\mathrm{G}_{\mathrm{ant}}: 38 \mathrm{dBi}$

- Maximum transmitter output power: $\leq+35 \mathrm{dBm}$ (it is the maximum possible transmit power, including tolerances, delivered to the antenna connector)

\section{Microwave e-band Radio Product}

A typical microwave radio consists of an IDU (indoor unit), ODU (outdoor unit) and antenna (dish). The ODU is connected to the IDU via IF (Intermediate Frequency) cable and also attached to the dish for connectivity with other radios. The ODU consists of baseband circuitry, modulator/demodulator while IDU communicates with BTS (e.g. eNodeB). The typical distance between IDU and ODU can be in the range of 70$150 \mathrm{ft}[6]$.

Contrary to typical microwave units, the e-band radio does not have an IDU. The entire circuitry is in ODU, which is attached to the 30 or $60 \mathrm{~cm}$ antenna (dish). A Power over Ethernet cable (one cable connection) runs from the unit via power injector to the BTS (for example, eNodeB) as shown in Fig. 4. The cable carries three sets of information namely operations and monitoring information, Ethernet traffic and power. Another possible setup is to run an optical cable from ODU to BTS for traffic and monitoring information and DC power cable $(-48 \mathrm{v})$ also from ODU to the power cabinet.
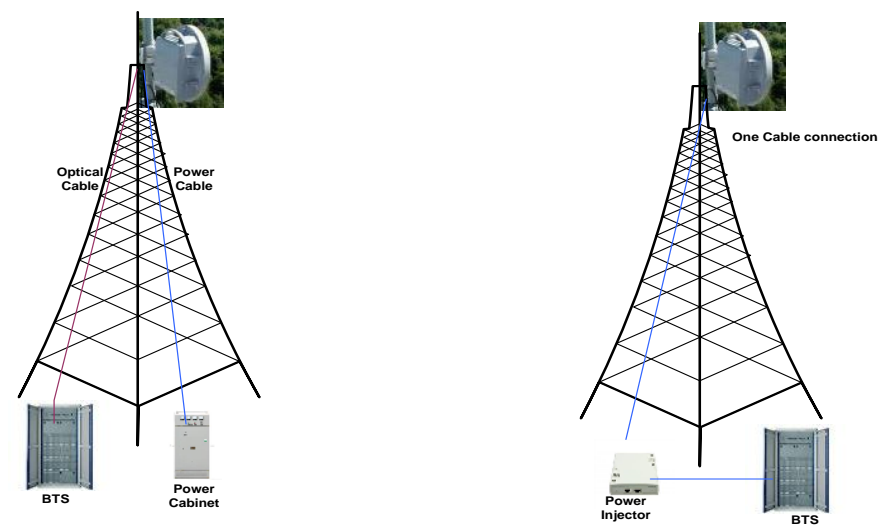

Fig.4. E-band radio setup

\footnotetext{
${ }^{\mathrm{b}}$ EIRP refers to the radiated power relative to an isotropic antenna for which transmit antenna gain is 1 [3].
} 


\subsection{Product Aspects}

The very first e-band products started to appear in the middle/later part of first decade primarily supporting 1 Gbps capacity in a $1.0 \mathrm{GHz}$ channel. The key pioneers were three USA based suppliers namely Bridgewave Communications, Gigabeam Corporation, and E-Band Communications. In the earlier part of the current decade the tier-1 manufacturers like NEC, Alcatel-Lucent and others started to offer such radios under their own brands as re-sellers. The resale agreements with the technology pioneers, made the first generation products more expensive carrying same features, but provided these radios more powerful branding. The much improved second generation radios from some teir-1 manufacturers are now coming into the market. The key product aspects of these two generation radios are shown in Table 3.

Table 3. E-band radio product specifications [7-11]

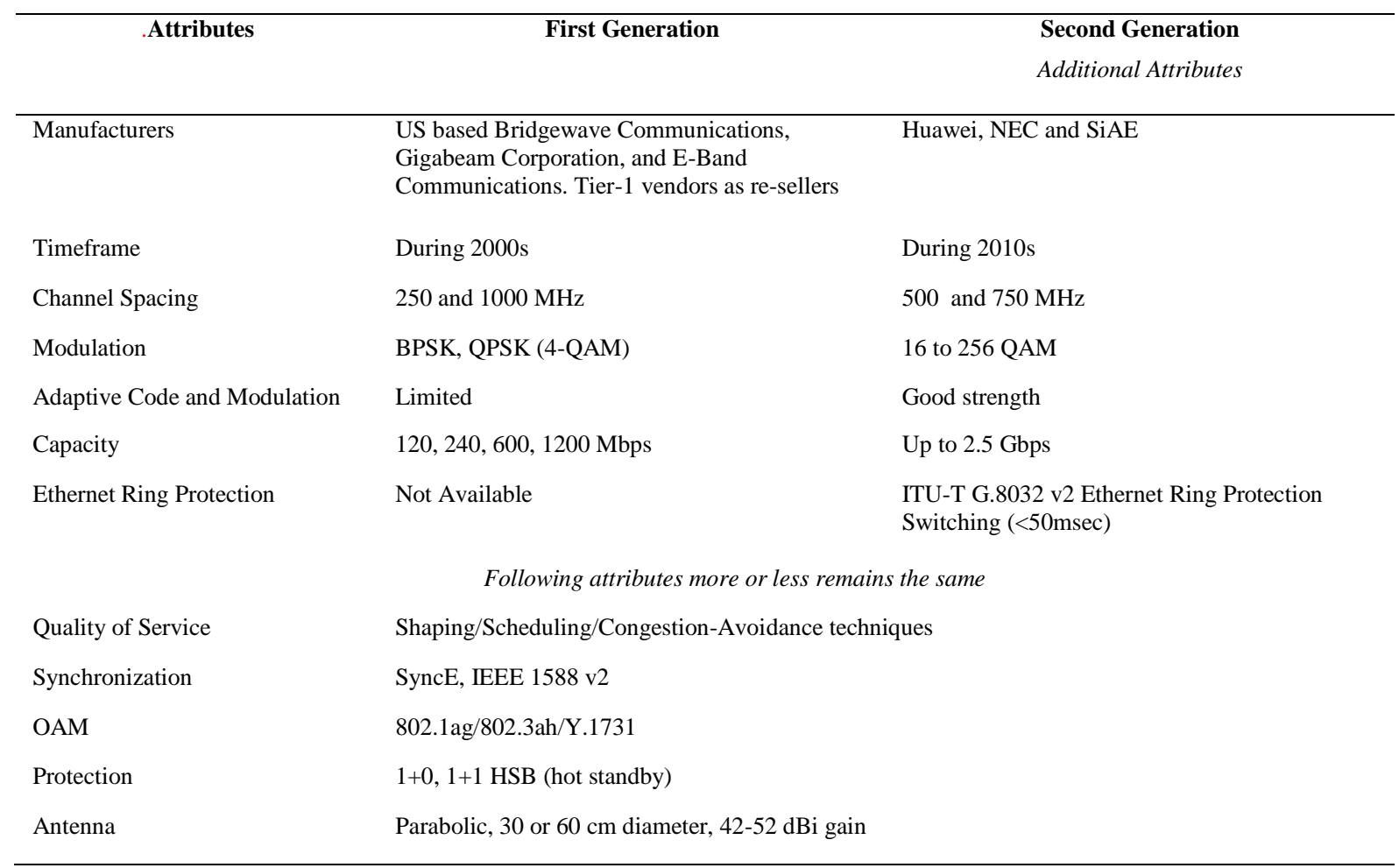

\section{Experimental Testing}

Fig. 5 shows a typical mobile backhaul segment of the cellular networks of Pakistan. One to three microwave radio hops are deployed to reach a core location in urban cities. The core location holds BSC/RNC, may also include core elements like MGW (media gateway) and SGSN (serving GPRS support node) and connects to MSC (mobile switching center) and GGSN (gateway GPRS support node) through optical fiber. In case of LTE, the EPC location consists of MME (Mobility Management Entity) and Serving/Packet Gateways.

In order to meet the future demands of voice and particularly data it was understood that current microwave radios are insufficient and extension of optical fiber to traffic aggregation hub sites and to BTSs needs to be taken into consideration. However, this extension is costly and full of right-of-way challenges. Thus the service provider evaluated an alternative 'e-band microwave radios'. 


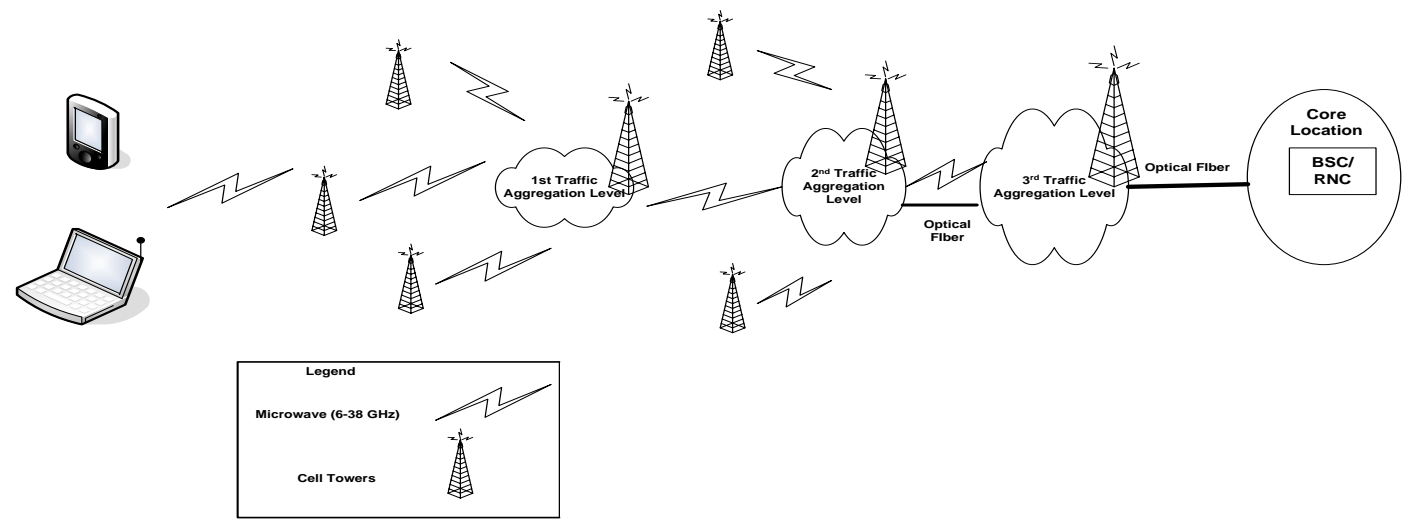

Fig.5. Mobile backhaul (Pakistan cellular market)

Simulations have shown e-band radios are tends to be effective as long as the hop length is less than $2 \mathrm{~km}$. Once the distance crosses this threshold it gets difficult to meet the criteria of $99.999 \%$ radio link availability. The limitation factor is high frequency band and high rainfall rate in the country. Pakistan faces heavy monsoon rains that last for about 3 months (July - September) every year. During this time the total rain accumulation is around $800 \mathrm{~mm}$ while daily could exceed $80 \mathrm{~mm} \mathrm{[12].}$

In major metropolitan cities the link distance between sites and between aggregation sites ranges from close to a kilometer to 3-4 kilometers. There are only a handful of core locations in urban cities making those hard to reach via e-band radios from the BTS sites. However, sites that require high transmission capacity and are less than $2 \mathrm{~km}$ from each other, or from traffic aggregation hubs or from core locations can use such microwave radios.

Keeping the above mentioned considerations, $1.0 \mathrm{~km}$ or less hop lengths were selected in an urban city. The service provider evaluated both first and second generation products at same and different times of the year including monsoon season for about 2 years.

\subsection{First Generation Product Testing}

The first generation e-band radio (a reseller product) was analyzed against certain standard microwave radio parameters and some specific to such radios. A $1.0 \mathrm{~km}$ point to point microwave radio link was set up in $1+0$ configuration with a $0.3 \mathrm{~m}$ dish for assessment.

The product supports 120, 240, 600 and $1200 \mathrm{Mbps}$ of capacity with 250 and $1000 \mathrm{MHz}$ channel sizes using BPSK (Binary Phase Shift Keying) and QPSK (Quadrature Phase Shift Keying) modulation schemes.

The RFC 2544 (Benchmarking Methodology for Network Interconnect Devices) [13] was used to check viability of carrying Ethernet traffic. This test was performed by generating traffic through an analyzer. The results of three performance indicators namely throughput, latency, and frame loss were found to be satisfactory. QoS (quality of service), SyncE (Synchronous Ethernet), scheduling mechanism and adaptive modulation were tested and found out to be satisfactory.

During the monsoon season, however a number of deficiencies were observed in the first generation product. Firstly, radio link failures were observed at $73 \mathrm{~mm}$ above rainfall that lasted for few seconds and occurred several times resulting in dropped calls (voice) and discontinuation in data sessions. The link was operational at 1200 Mbps with QPSK having a threshold level of $-64 \mathrm{dBm}$ at @ $10^{-6}$ BER (bit error rate). The product only provides RSL (received signal strength) which is similar to BER as shown in Fig.6. Fig. 6 is a sample alarm snapshot where major RSL results in radio link failures. Also, higher latency and high frame error rate during some Ethernet performance tests were also witnessed. Overall, the under trial first generation radio was turned out not to be a carrier grade microwave radio product. 


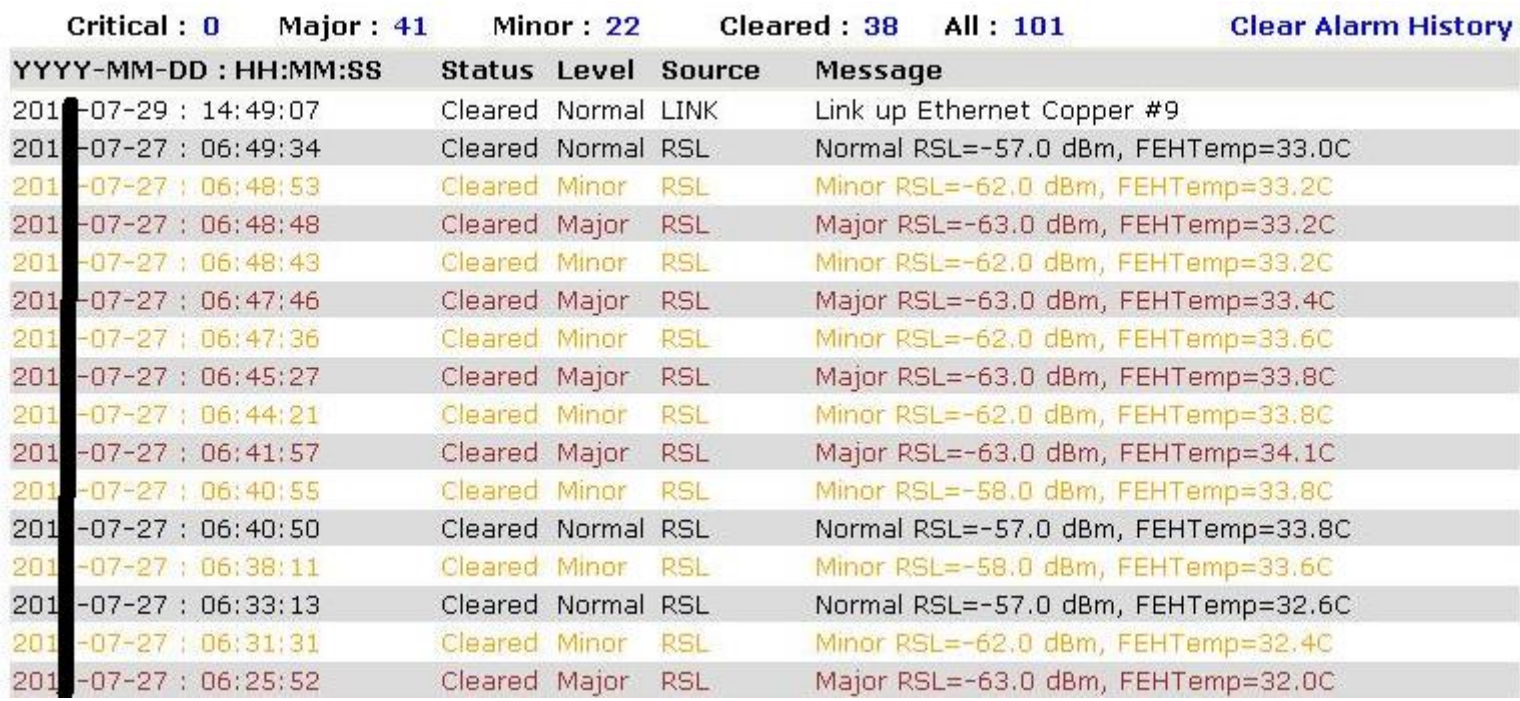

Fig.6. Radio link failures (at major RSL)

\subsection{Second Generation Product Testing}

The second generation product though in beta form comparatively gave a better performance. The radio supports capacity ranging from 390 to $1560 \mathrm{Mbps}$ in a $250 \mathrm{MHz}$ channel using QPSK, and 16/32/64/128/256QAM (Quadrature Amplitude Modulation). It may be noted that the product supports higher capacities than prescribed by the standard (Table 2) using same and better modulation schemes which is obviously beneficial for the telecom sector. The testing was executed for six months including some part of the monsoon season. The overall test results were positive and link didn't fail even at $80 \mathrm{~mm}$ rainfall.

The interesting element of this evaluation was the test setup comprised of 3 hops connected in a ring topology. The distance between any two hops was less than $1.0 \mathrm{~km}$ as shown in Fig. 7. This configuration was used to demonstrate the feasibility of such radios as an alternative in ring topologies that are normally turned up with optical fiber cables. The OFC (optical fiber cable) rings are supported with 50ms restoration time in case of a cut. Similarly, the second generation e-band radios support ERPS (Ethernet Ring Protection Switching) which also operates at the same protection level (sub-50ms).

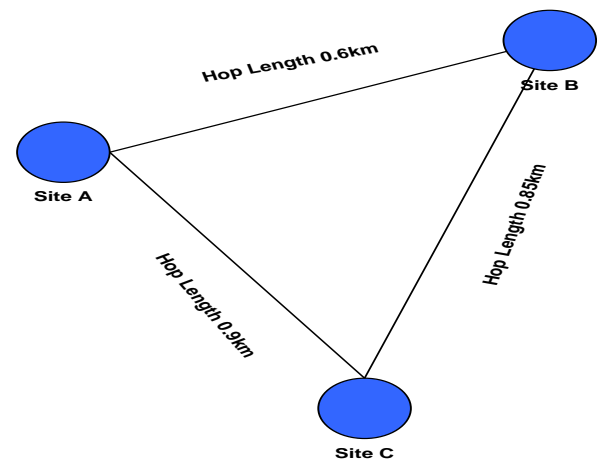

Fig.7. Radio link failures (at major RSL) 
Various tests were executed using this ring configuration and all passed successful. A test tool was placed at Site A for various test cases including for Gigabit Ethernet performance testing over the ring network. The test tool is capable of testing and maintaining Ethernet, Gigabit Ethernet, IP, and Fiber channel services. This was a very positive outcome making e-band radios a strong, cost effective alternative to optical fiber both in point-topoint and in ring setups.

\subsection{Gigabit Ethernet Testing}

The Ethernet performance was measured to ensure that exchange of information is properly taking place and also adhering to the required levels. This was confirmed by testing the bandwidth, the delay and the loss of frames in the connection. In Ethernet terms these are called Throughput, Latency and Frame Loss respectively [14]. Ethernet performance can be measured using the criteria of RFC 2544. RFC 2544 specifies certain test criteria that allow the service provider and customer to reach an agreement. RFC 2544 requires the standard frame sizes $(64,128,256,512,1024,1280,1518$, and 1522 bytes) to be tested for a certain length of time and a certain number of times. The performance was measured at Layer 2 using RFC 2544. The product supports multiple GbE/FE (Gigabit Ethernet/Fast Ethernet) ports up to a maximum of 3 ports where a maximum of $1 \mathrm{Gbps}$ can be provided via a single port.

The traffic was generated through the above mentioned tester, and the four performance indicators were measured over the ring. Various frames sizes of RFC 2544 were tested for the various supported rates, bandwidths, and modulation types. The product also supports jumbo frames such as 9000 byte frames, which was also tested on different modulation schemes. One such result with 256-QAM and $250 \mathrm{MHz}$ bandwidth is shown in Table 4.

Table 4. Gigabit Ethernet performance results with 256-QAM modulation

\begin{tabular}{cccc}
\hline $\begin{array}{c}\text { Frame } \\
\text { Length (byte) }\end{array}$ & $\begin{array}{c}\text { Throughput } \\
(\mathbf{M b p s})\end{array}$ & $\begin{array}{c}\text { Latency ( } \boldsymbol{\mu s}) \\
\text { Threshold } \\
(\mathbf{2 0 0 0} \boldsymbol{\mu s})\end{array}$ & $\begin{array}{c}\text { Frame loss (\# } \\
\text { of lost frames) }\end{array}$ \\
\hline 64 & 2000 & 245 & 0 \\
128 & 1800 & 298 & 0 \\
256 & 1690 & 313 & 0 \\
512 & 1642 & 339 & 0 \\
1024 & 1616 & 403 & 0 \\
\hline
\end{tabular}

\section{Suitability for Pakistan}

As indicated earlier, Pakistan cellular market is one of the lowest if not the third lowest mobile ARPU in the world according to some studies. The ARPU figure has not changed even after completing one year of $3 \mathrm{G}$ launch. In such a market extending fiber in the space of mobile backhaul and/or to the cell sites is not a cost effective option [15]. Some examples where e-band radios can be used are as follows:

OFC vs. e-band radio: Although, OFC vs. e-band radio is not an apple to apple to comparison, a high level analysis showed significant savings. For example, e-band radios will provide $40 \%$ savings in CAPEX (capital expenditure) and 60\% in OPEX (operating expenditure) as compared to OFC for the ring topology shown in Fig. 7. Beside cost, OFC faces longer deployment times and right-of-way challenges.

Redundancy to Fiber: These radios can provide a redundant path for carrying traffic along with optical fiber. These are suitable for second or third level backup for existing and new fiber routes.

Frequency relief: The traditional microwave radios have smaller channel bandwidths (largest is $56 \mathrm{MHz}$ ) as 
compared to e-band radios (250 MHz is the minimum) and thus have lower capacity to carry traffic. Many operators due often face shortage of such frequencies and utilize many channels at transmission hubs to support traffic backhauling of various individual (dependent) cell sites. Thus, e-band radios can be used to free up some traditional microwave frequencies at high capacity sites.

Tower loading relief: An e-band radio can accommodate capacity of at least 2-3 traditional microwave radio units. Thus, it reduces the loading on cell towers making room for future use.

Security Situation/Emergency Relief: In the events of natural disasters or manmade upheavals, cell-onwheels equipped with e-band radio can be used to address relief efforts as an alternative to fiber.

\section{Conclusion}

The results showed that second generation e-band microwave radios are more robust than their predecessor and can be used in $3 \mathrm{G} / 4 \mathrm{G}$ mobile networks. Such radios are also under considerable discussion as a potential mobile backhaul solution for $5 \mathrm{G}$ networks [16-17].

The successful execution and positive outcome of these radios in ring configuration further shows their viability as an alternative to OFC in mobile backhaul. At the same time it may be noted that these radios cannot replace fiber and can't be as robust as OFC. However, these do provide a cost effective, quicker deployable alternative with negligible right-of-way issues in comparison to OFC in the critical space of mobile backhaul.

\section{References}

[1] Asif, SZ. et al. An Evaluation of Future Mobile Networks Backhaul Options. 5th Int'l. Conference Wireless and Mobile Communications, Cannes/La Bocca, France, Aug. 23-29, 2009, pp. 146-51. 2009.

[2] Pakistan Telecom Authority. Telecom Indicators http://www.pta.gov.pk/index.php?option=com_content\&task=view\&id=269\&Itemid=658. 2015.

[3] ECC with CEPT. ECC Recommendation (05)07. Radio Frequency Channel Arrangements for Fixed Service Systems Operating in the Bands 71-76 and 81-86 GHz. February 2009.

[4] Wikipedia. http://en.wikipedia.org/wiki/Main_Page.

[5] ETSI. ETSI EN 302 217-3 (V1.3.1) Fixed Radio Systems; Characteristics and requirements for point-topoint equipment and antennas; Part 3: Equipment operating in frequency bands where both frequency coordinated or uncoordinated deployment might be applied; Harmonized EN covering the essential requirements of article 3.2 of the R\&TTE Directive. 2009.

[6] Lehpamer, H. Transmission Systems Design Handbook for Wireless Networks, USA: Artech House, Inc.; 2002.

[7] Bridgewave. $80 \mathrm{GHz}$ Wireless. http://www.bridgewave.com/products/80ghz.cfm

[8] E-Band Communications, LCC. 4G Evolution Series. http://www.e-band.com/ProductOverview

[9] Huawei. E-band Microwave. http://www.huawei.com/en/solutions/broader-smarter/hw-196711.htm

[10] NEC. iPasolink EX. http://www.nec.com/en/global/prod/nw/pasolink/products/ipasolinkEX.html

[11] SiAE. ALFO plus 80 series. https://www.siaemic.com/index.php/productsservices/telecomsystems/mwsys/25-inside-articles/53-alfoplus80

[12] Faisal, N. et al. Third Successive Active Monsoon over Pakistan - An Analysis and Diagnostic Study of Monsoon 2012. Pakistan Journal of Meteorology 2013; 9(18):73-84.

[13] IETF RFC 2544. Benchmarking Methodology for Network Interconnect Devices. March 1999.

[14] Agilent. RFC 2544 Testing of Ethernet Services in Telecom Networks. 2004.

[15] Asif, SZ. Next Generation Mobile Communications Ecosystem: Technology Management for Mobile Communications. UK: Wiley Inc.; 2011.

[16] Monserrat1, JF. et al. METIS Research Advances towards the 5G Mobile and Wireless System Definition. EURASIP Journal on Wireless Communications and Networking. 2015. 
[17] Radio Spectrum Policy Group, European Commission. RSPG15-607: RSPG Report on Spectrum issues on Wireless Backhaul. 2015.

\section{Author's Profile}

Saad Z. Asif ${ }^{\mathrm{c}}$ has more than 17 years of experience in evaluating telecommunications standards and technologies, providing strategic directions to companies and advising government on telecommunications matters. Currently, he is working as a Director Telecom Wireless at Ministry of IT, Pakistan drafting country's Telecom (Wireless and Spectrum) policy and leading the WRC-15 (World Radiocommunication Conference 2015) activities. He worked till 2014 at Telenor Pakistan as Senior Advisor- Transmission Network where his focus was on millimetre wave e-band microwave radios and carrier Ethernet technologies. He also previously worked for well known cellular operators Mobilink, Pakistan and Sprint, USA where he conducted proof of concepts trials on WiMAX, and 3G CDMA2000/EV-DO respectively. He also played a major role in designing Sprint's wireless high-speed data strategy. He is a recognized Scientist of Pakistan, holds five U.S. patents, has written two books on telecommunications and publish 14 technical papers/articles, and holds M.S. in electrical engineering and engineering management from Oklahoma State University, USA and University of Kansas, USA respectively.

How to cite this paper: Saad Z. Asif,"E-band Microwave Radios for Mobile Backhaul", IJWMT, vol.5, no.4, pp.37-46, 2015.DOI: 10.5815/ijwmt.2015.04.04

\footnotetext{
${ }^{c}$ Disclaimer: The responsibility for the content of this article rest upon the author, not with his employers (current and any former).
} 